
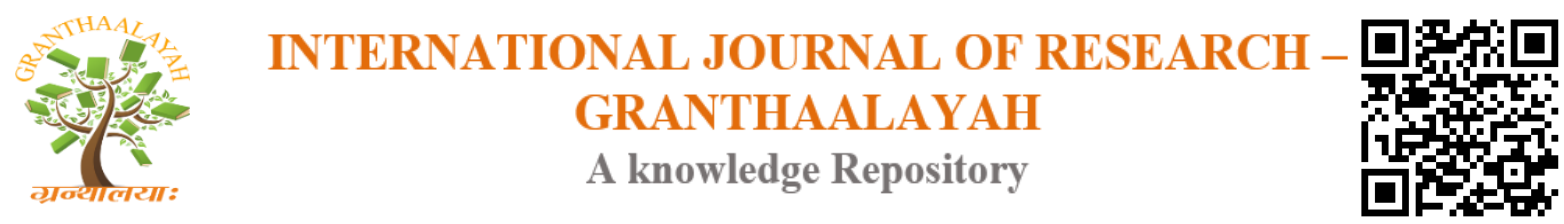

Science

\title{
OBSESSIVE-COMPULSIVE PARTICULARITIES BEFORE AND AFTER REMISSION OF ACUTE PHASE EPISODES OF SCHIZOPHRENIA
}

\author{
Ana Miruna Dragoi ${ }^{1}$, Angela Enache ${ }^{2}$, Ilinca Vlaicu ${ }^{3}$, Amelia Damiana Trifu 4 \\ ${ }^{1}$ Clinical Hospital for Psychiatry "Alex. Obregia”, Bucharest, Romania \\ ${ }^{2}$ Hospital for Psychiatry Sapunari, Sapunari, Romania \\ ${ }^{3}$ Faculty of Pshychology and Education Science, University of Bucharest, Romania \\ 4 “Tudor Vianu" National College of Computer Science, Bucharest, Romania
}

\begin{abstract}
Motivation/Background: We aim at presenting a case that would circumscribe to the concept of schizo-obsessive disorder, in which the onset at the end of adolescence was with OC phenomenology, the negative symptoms appearing subsequently, while the productive perceptual and ideational area (auditory hallucinations and pseudohallucinations, next to the reference delusional ideation and Kandinsky Clerambault syndrome) developed at about one year and a half after social insulation. To be noticed that in residual phases, OC phenomenology acquires other connotations than those prior to schizophrenia onset, the patient never acquiring again a total insight on the disorder.

Method: Computed EEG, psychiatric interview, psychodynamic interview, psychiatric and psychological monitoring of daily evolution under treatment, life map, heteroanamnesis, psychological tests, psychodynamic interpretations.

Results: According to Poyurovsky's guide, the case circumscribes to the diagnostic of schizoobsessive disorder. When obsessions and compulsions were related to the content of delusional ideas and hallucinations, other typical rituals of obsessive-compulsive disorders appeared too, the patient considered sometimes irrational and excessive.

Conclusions: Social degradation of the patient is dictated mainly by the negative dimension of schizophrenia, secondly by energy consumption in fulfilling the rituals and compulsions and last but not least by the mood change in depressive sense.
\end{abstract}

Keywords: Schizo-Obsessive Disorder; Partial Insight; Pseudohallucinations; Rituals; Hypermnesic Mentism; Paranoid Fears.

Cite This Article: Ana Miruna Dragoi, Angela Enache, Ilinca Vlaicu, and Amelia Damiana Trifu. (2019). "OBSESSIVE-COMPULSIVE PARTICULARITIES BEFORE AND AFTER REMISSION OF ACUTE PHASE EPISODES OF SCHIZOPHRENIA.” International Journal of Research - Granthaalayah, 7(7), 79-92. 10.29121/granthaalayah.v7.i7.2019.719. 


\section{Introduction}

\section{Schizo-Obsessive Disorder- Clinical Entity?}

In patients with schizophrenia, the obsessions and compulsions can pre-exist, can occur spontaneously during psychosis or they can be precipitated or exacerbated by the anti-psychotic medication. In some cases, the obsessive-compulsive symptoms remain distinct. [1] The insight on their rationality is present, they are being felt as excessive and ungrounded. [2]

In other cases, obsessions and compulsions become subject to a delusional elaboration during active phases of psychosis or obsessional symptoms are inseparable of psychotic symptoms. [3]

Unlike phobias, in which the subject fears of something outside him, in obsession, the fear targets even the acts of the subject, there being the question of inner tension reported to what the patient himself does. [4] The anxiety is considered secondary to the reception of content of obsessive intentions to perform an aggressive act.

In the classical concept of Pierre Janet on neuroses, within the psychasthenia concept, the author also approached the obsessive-compulsive disorder, as being a perturbation in perception and synthesis of the time lived. [5] We are discussing on an elaboration of the subjective "present", an authentic insertion of the person in question in the given reality: the synthesis of the present is based on the act, behaviour in which the subject is engaged. [6]

The central aspect of the psychasthenia, which leads to obsessions, is considered to be the feeling of "incompletion and imperfection". The following phase of the disorder is that of obsessions and compulsions. The ideas and involuntary drives appear very easily and frequently, dominating patient's life. [7]

As a conclusion in the present case, the obsessive-compulsive symptoms of the patient represent a clue of disorder seriousness and as "filiation" they are closely related to paranoid delirium. [8] Specialty literature of the last years shapes the existence of a schizo-obsessive nature disorder, in the present case the mechanism being the following:

The patient onsets as authentic schizophrenic, where delirium is of persecution, preponderantly focused on the parents, in relation to whom he presents affective inversion. [9] The parents want to hurt him, when there appear certain auditory triggers, such as strong noises, screams, bangs, or motor triggers (rushed walking, haste in the execution of activities), moments that are possible on the background of a sensorial perceptive mood (a generalised decrease of sensorial thresholds, this pathology being renown in schizophrenia). [10] To defend against these images that come accompanied by strong anxiety and fear, the patient manifests specific compulsions: touches the doorknob six times precisely, repetitively checks his money he keeps in the house in the drawer in a certain position, repeats verbal or attitudinal rituals within dialogue, etc. [11]

He feels that both triggers, as the images that come in his mind are imposed to him and he must face them by these behaviours, the fact occupying most of his time and making him incapable of carrying out any other useful social activity. In the category of "fixations" there is also included the preoccupation for the actress Kate, presence he feels as "unwanted" in his mind and "imposed": "She is the one and only chosen unwillingly. I did not choose her, it is not as if I can choose 
between her and Pamela Anderson, so to say. But I watch her, and her face is perfect. And this matter!"

He frequently draws pentagrams of perfection, where perfection is interpreted as happiness, it having as antonym suffering. These are called IMA's collections (his initial letters), where he is to collect toys.

\section{Childhood}

He asserts at young ages the sobbing spasm and frequent moments of lipothymia. He was preoccupied of masturbation and he relates that he was pottering: "I was jumping in bed; I was bouncing around the house" to control the mood. He was accusing "memory erasure" from childhood, but he puts the question if many events were reinterpreted after having triggered the disorder or if psychotic perturbations existed since that (conceptual disorganisation, logical association weakening, non-selective retrospections delusionally integrated are).

\section{School History}

He attended Tonitza Arts High School, he sat for Baccalaureate exam that he felt as being a difficult exam. There followed the admission to the Institute of Plastic Arts, with the drawing test "a female model", exam he failed.

A period of three-five years he stayed home, and then he attended the Faculty of Theology, being prompted by his parents (the two twin brothers, twelve years older, were going in the same direction, brothers on whom the patient relates that he never coped with). After one year and a half, he interrupted his studies, the delirium influencing both his focusing capacity, and his memorisation at creativity level, losing his capacity to do something.

Being asked how he perceives the causality of his disorder, we identify a simplistic infantile thinking, in which all reduces to only one aspect: "My parents are divorced and everything is understood from here: There were discussions, scandals, and I did not want to be included". (the divorce of his parents took place when the patient was 5 years old, and his twin brothers 16 years old).

\section{Professional History}

For a very short time interval (approximately one week) he worked as call center operator: "They were saying I did not meet the necessary conditions. They were mean to me. (nobody assumes decisions, everything is made under a locus of an external control)

Professional life is vaguely represented in mind, he recalls that around the age of 29-30 years, he also tried to work at the painting workshop of a church, but he did not get along with those from that place. His accounts are made with sensitivity, even if his mood changes quickly in a superiority smile subsequently.

\section{Relational History}

He had a girlfriend for five years, he being 25 years old, and she 27 years old, relationship within which during the first two years they had no sexual contacts, on the ground that she did not agree with it. After this period, intimate contacts existed, but unsatisfying for the person in question, 
because she did not correspond to his wishes. Subsequently, he developed a jealousy delirium, being left by his partner. As regards the intimate life, he relates fragmentary delusional ideation: "There were some sexual schemes, and I was the one who controlled them, too."

The interactions from the social circle were weak, feeling exclusion: "I did not get along with anybody; I never in my life had friends."

\section{Medical History}

He was diagnosed with paranoid schizophrenia in 2015, when he developed delusional jealousy ideation, in parallel with the feeling that something bad is happening to him, which my parents and my brothers are stronger than him. The first hospitalisation lasted one month.

The second hospitalisation was following a marking episode of negative symptoms and hallucinating phenomena: "I stayed dirty. Life and hope did not really count. I was staying backwards, and they were coming towards me, they were hitting out at me, so humpback...I could even speak, because I had limits verbally..."

The third episode was two years ago, on which he relates that: "I could not go to bathroom, I was staying with poop and pee on me and I was eating from the kitchen floor." The negative dimension of schizophrenia is conspicuously identified, the patient not leaving his domicile during the last year, not leaving even his bedroom, reaching to foul next to his bed: "I was staying dirty I the house". He was asserting that he had reached to eat from the floor because of his overwhelming psychotic distress to the thought of exiting the room, distress that was paralysing his physical movement power, with incapacity of reaching to the toilet.

\section{Materials and Methods}

Initial psychological evaluation, as well as the progressive one, the structured and unstructured clinical interview, the life map, psychoanalytic psychotherapy cure, periodical psychiatric evaluation and treatment monitoring, analysis of transference and countertransference dynamics, psychoanalytic interpretations, explanatory models of psychodynamic orientation, patient reporting to his own unconscious, the analysis of his social functioning, the study of works, the transgenerational analysis, psychological monitoring and psychiatric treatment.

\section{Results and Discussions}

\section{Perception Disorders}

Auditory hallucinations and pseudo-hallucinations, voices that are chatting one to the other, or who are commenting the actions of the patient, sometimes with favourable content, sometimes unfavourable. He prefers disorder, even if he lives in misery: "I am not perfectionist, but I want to be order...Aoleo! Are they speaking about us?" (quasi-present hallucinations during the interview)

Illusions and visual hallucinations. 


\section{Delusional Interpretations}

His parents bought him a computer, where "strange things" happen, such as the pages moving in the browser, thing which is delusionally interpreted.

Ads that appear on the internet are perceived as being put by his father, the speech is disorganising and he loses his logical course.

\section{Thinking Disorders}

"My parents want to hurt me, willingly and unwillingly" (delusional ideation of persecution addressed to his family, built with high probability on the affective inversion towards them).

Suicidal preoccupations are identified: "I was a little depressive, I wanted to commit suicide, but it was just a thought." (depressive intrusions, recurrent death thoughts that can determine suicidal conduct).

"A neighbour has stolen my antivirus and I have searched her everywhere, but I don't know her name."

"My brothers and my parents do not take care of me; they do not communicate with me. I neither communicate with my brothers; they do not want to open towards me." (projection mechanism)

"I feel abandoned." (regressive behaviour, anguishes of Ego annihilation to abandonment, attachment pathology).

"I touch one object more times and if they are catcalling me when I do this, I respond violently. I do not feel well if things aren't put in order." (overlap of obsessional phenomena in schizophrenia).

"My parents control me by their attitudes. How would it be that they are moving more quickly or slower. I realise it according to the way they enter my room. Then, they are closing the door so that I cannot breathe anymore." (hyper-analysis of other people's actions, interpretativity of phenomena of external world, assignment of significances, xenopathic control, delusional influence ideation).

"They are taking care around me and not of me! I soiled myself if I could not do anything else." (regressive behaviour of territory marking, of defiant opposition, characteristic of animal register). "Nobody behaves nice to me!" (relationship sensitivity, existential loneliness).

"I do not hear voices, but things happen to me by telepathy. Foreign thoughts can be inserted in the head. Somebody controls my mind by attitude." (delusional influence ideation, transmission of thoughts, Kandinsky-Clérambault mental automatism syndrome, also incorporating pseudohallucinations).

Upon the extension of anamnesis, he recognizes inclusively the presence of verra auditory hallucinations, next to the delusional ideation of mystical colours: "I hear foreign voices and I communicate with imaginary persons. With God, who has a black armour. I sometimes had a dialogue and we spoke more." 
Under psychiatric medication for months, the patient starts to confront the reality plane versus the plane of communication with God. His delusional system becomes elliptical, the person in question not confessing it, because he lacks the sense at times: "I cannot say some things, I don't know them or I can't."

Regarding his religious behavior, he asserts: "To say that yes, I am faithful, I do not have any mystical experiences. I do not communicate with God anymore." He recognizes in antecedents the practice of some long prayers, for hours.

We can note the triple automatism (of thoughts, of feelings, and of actions) as nucleus of xenopathy and non-appurtenance to Ego.

"They took me by force. I was forcing myself and I was vomiting by abdomen contraction, because I can do this because I have a big tummy." (illogical explanations, by contiguity, infantile)

"I was hypnotised, somebody outside wanted to hurt me" (delusional control ideation, persecution) "I do not feel free, I feel that somebody cast spells on me, because I feel my heart is swelling. What else could it be?" (delusional relationship ideas, belief in spells, delusional interpretativity of certain visceroceptive sensations).

"I feel that people can read my mind" (mind reading phenomena)

"I would like to be active physically, but some people do not allow me, by scandal and violence." (xenopathic control)

"If I am thinking to something, the respective thought enters in me, not only in my head, but also in my body." (intrusive thoughts, control from a distance)

"I do not really know how it is in my mind...I knew when I was little, but I forgot...Now I how other type of mind, I am speaking with Gods..." (personification of thinking)

"Five years ago, I felt my soul rises from my body." (bizarre experiences, of body strangeness) "I feel some limits as regards cleaning, I could do this only if I do it simultaneously in the two rooms, but I can't do it, because I am not God" (illogical construction)

"They are controlling me telepathically, I do not hear them, but they are in my mind." (delusional ideation of xenopathic control)

Food appetite disorders

"I frequently get sick and I vomit. I do not feel the need to eat."

\section{Erotic Sexual Life}

The patient asserts that maybe he has too big demands: "In my mind I would like to last three hours. Three hours per day, I mean...After which it depends what we have in the schedule, too...films...or something else...I would like to meet, to know what sexual needs man and women have ..." 
"I felt a danger If I was masturbating thinking to her...And now I feel the devil takes me... and the police would come too...I felt a real danger when I masturbate and I was ejaculating... The devil was taking me...I was suffering because I hit myself in the mouth...And I was looking to pictures on websites..."

\section{Reporting to Immediate Environment (House)}

He feels alone and he calls regressively his mother to stay in bed with him, but she asserts that she does not have anything to do in his room. He countered that the longest period when she stayed with him was 25 minutes.

He cannot sleep in his bed because he feels a bad thing of depressive type.

During daytime, he goes to sleep in his father's bed, where he can rest.

What upsets him most is that his parents stayed together, even if they were divorced, while they, the children, do not have their homes: "They were quarrelling before, now they only raise the tone ..."

"They are two teams of two persons against only one man!"

"When they don't enter my rooms, I really feel myself...And then I feel entitled to clean...They are cleaning using the mop...I felt humiliated many times... The bed linen stinks a little of dirty, not of perspiration, because there is some time since I changed it ..."

"When I was little, they did not take care of me as I would have wanted... They do not take care of me now either (he is looking at his nails) ..." (easy sliding from concrete to symbolic, derealisation feelings)

\section{Related to Humiliation Feeling, He Relates}

"tension is imposed with a certain purpose by the behaviour of hospital attendants."

He speaks with pleasure about Songoku drawings, where the character, by his psychical power changes inside. (regressed behaviour, specific to pre-school age)

"I feel well, I am not gay. My parents tell me I am homosexual and that I attract evil."

"I don't have low energy; I have very high energy! I must control physically."

"God has what sex he wants!"

"I must write on a sheet of paper all the things in the house...to make an analogy... a connection between objects... and I do not feel to do this..."

"Ifeel for my parents a forced affection, Ifeel that they were behind the computer...there are three things...three in one...I am convinced that they, when they are going to bathroom, do this to masturbate ..."

\section{Kate}

He is very in love with an actress from "The world beyond", he wrote her and he believes that it is possible to be with her and get married. 
"I cannot say I am ashamed...If I had fifteen women in my life, she had three or up to five men...Don't you think by any chance that I am living in one world and she in another one? Because she did not answer to my message ..."

"Sexual images with Kate in erotic shows come to my mind and I do not accept the idea that she could be with another man, because I am jealous and I have the drive to beat all those in her show or the parents who, in fact, are behind these thoughts."

\section{Future Plans}

"I don't do what I want. I would like a job."

"I would like to have friends, a girlfriend and health. I cannot have health and friends, because of the parents. My parents do not change, they are telling me my friends teach me to make foolish things."

"I cannot have a girlfriend; I am hindered by Facebook. I find only erotic and porno things on my new account."

"I feel shame of people and I know it is not appropriate. I feel fear if I talk to a girl"

"My demands are not high, I do not want eight women, I want one, two ..."

"As objectives, I have to pay for maintenance 80 RON, to throw the garbage at $17: 00$ and to let me bath when I want."

\section{Association of Obsessive-Compulsive Elements}

"If I make certain things when they come to my mind, I feel bad, I feel something in my stomach and heavy depression comes to me, starting from there."

"If I am late and I did not take the pills in time, I know I must be punished because I was to bathroom." (regressed, suggestible behaviour, with clinching to attachment persons towards whom he develops rituals as regards sitting and standing on/from the chair, greeting formulas, number and order in which they must happen). [12]

He perceives physical imperfections related to the dimension and appearance of his nose, saying that at a given time he provokes vomiting by the contraction of the abdomen to preserve his weight and form. (dysmorphophobia elements)

We find collectionarism, the need to preserve some invaluable things.

Relating from his childhood, he recalls how his mother was buying him cloths she was bringing to him, which he reinterprets delusionally at present: "I feel mocked I have clothes. She was coming to me with clothes and I could not beat her...If I have a thing, why should she bring me another one? I already arranged my things in a certain order and I had no place for what she was bringing to me!"

"I like order, that all be arranged alphabetically, to put my clothes from dark to light colours." As regards cleaning in both rooms, he relates preoccupations related to symmetry: "It is like I would have two lovers for whom you must be available at the same time. It should be the same with the two rooms, the same objects to be inside them, arranged in the same order. And then I 
could clean them! Otherwise, if I start to clean in one room and in the other one not, I start to be afraid of fighting and quarrelling, so that I'd better not. At the same time, if the personal objects are not arranged in parallel, in the middle and at equal distances (phone, cap, lighter), the same aggressive thoughts come to my mind..."

"When one thing does not come out as it should be, I make two steps backwards and I resume everything from the beginning, to hinder the anxiety state and to avoid violent acts I would perceive. I stay in tension and fear to be ok, to do things correctly in life."

"I remained blocked between states and maybe you can tell me how to exit. I feel that it hurts me, that I am not free, it is a kind of absolutely necessary need of which half is my will and half need. Bad thoughts are coming, related to beating, of envy, of jealousy, sexual thoughts are coming too... what should I do...how can I do..." (intrusiveness and recurrence to an ideation the patient perceives as being embarrassing and parasite, reaching Chaslin hypermnesia mentism). He perceives aggressive thoughts as being "inserted in his head" by the parents who entered by force his thoughts. They are required to be quiet by certain compulsions, he uses to defend against obsessive ideas.

"If I do not do those things (compulsions), I can neither advance, nor stop. I defend myself...I refuse violence...If I don't do them, the thoughts would become stronger and stronger, I could not refrain myself and I would start throwing things around, to break, to lift the table and finally to start fighting ... To escape, I hit myself and if I feel I hit too hard, I caress myself..."

The content of OCD obsessions is abnormal and often absurd, thing the patient notices and toward which he reacts by criticism and effort to remove obsessions.

There are cases when there is critical self-assessment of absurdity of expressed thoughts. When they have the form and intensity of some aberrant beliefs, the criticism decreases progressively. Therefore, during hospitalisation, as regards Kate, the patient tells that, however, what he thinks and feels for her make him well, they are exaggerate thoughts that consume his energy too much. Subsequently, following an event with stressing content, Kate reappears in the speech with the same strength.

\section{Treatment}

Even if he asserts that if he does not take his medication, he feels an inner void feeling, he reports to it in a paranoid manner, refusing help and considering in his narcissist fragility inacceptable to depend of something. [13] Symbolically, as in the case of any authentic paranoid, he has the feeling the medication changes his personality, not managing to preserve in his mind a continuum between him the symptomatic one and him under treatment. [14]

Current treatment: Risperidone $4 \mathrm{mg}$ tb $1+0+1$, Sertraline $50 \mathrm{mg}$ tb $1+0+1$, Timonil $150 \mathrm{mg}$ tb 1+0+1, Lorazepam $1 \mathrm{mg}$ tb 1+1+1, Diazepam $10 \mathrm{mg} \mathrm{1+0+1.}$

We can notice the need of association of an anti-obsessional antidepressant. [15] 


\section{Psychological Examination}

We can identify hypomobile mimics, reduced gestures, voice with low tonality, the presence of pseudohallucinations, lexico-informational volume limited to usual, simple words. The decrease of capacity of emotion contention, restraint of interest sphere and activities around psychic suffering, low frustration tolerance, increased suspiciousness.

Calgary scale highlights severe depression, patient dominated by negative thoughts of incapacity and lack of existential sense.

Luscher: emotive subject with perturbation of affective emotions, impressionable, with high sensitivity and soul receptiveness. He cries easily, of sadness, of pity and of tenderness. Any external hit can be felt with pathological intensity, depressing the one in question.

Schmiescheck questionnaire of accentuated tendencies: hyper-perseverance, extreme ambition, sensitivity, instability of emotions.

Tree test: splitting in three, corresponding to the metaphor of non-separation regarding the parents, self-limitation, infantilism, "to identify himself from nothing".

\section{Experimental psychodiagnostics of drives (Szondi test):}

In the foreground:

Vector $\mathrm{S}=\mathrm{h}+\mathrm{s} 0$ : dominant of infantile type love, with satisfaction acquisition from aggressiveness.

Vector $\mathrm{P}=\mathrm{e}-\mathrm{hy0}$ : accumulation of anger, revenge, envy and jealousy, suggesting Cain constellation (e-) without moral brake (hy0).

Vector Sch = k-p \pm : the use of mechanisms of negation and projection, which leads to estrangement and finally to alienation; abandonment, incapacity to define his own genre, depersonalization feelings.

Vector $\mathrm{C}=\mathrm{d}+\mathrm{m} \pm$ : obsessional ambivalence in attachments, which leaves space for some paroxysmal depression outbreaks, Ego being introjected.

Perspective profile:

Vector $\mathrm{S}=\mathrm{h}-\mathrm{s} \pm$ !: sadomasochism ( $\mathrm{s} \pm$ ) with Eros suppression (h-), namely aversion towards people in general; aggressive tendencies inhibit the need of culture and civilisation, the self-love lacks, Ego being in overpressure, with risk of extreme sadism.

Vector $\mathrm{P}=\mathrm{e}+\mathrm{hy} \pm$ : for the future, the Abel nature will defeat the Cain one of the present, the patient exteriorising his kindness, even if he will do it in demonstrative manner; he will reduce his dilemmas and moral doubts by assumption of guilt; the flow of emotions (e+hy+) will tend to concealment (hy-), leaving space for phobic pathology (e+hy0).

Vector $\mathrm{Sch}=\mathrm{k}+\mathrm{p} 0$ : total introjection in a schizo-obsessive type profile.

Vector $\mathrm{C}=\mathrm{d}-\mathrm{m0}$ : clinching, perseverance, conservatism, anal character expressed psychopathologically in a delirium with histeriform roots.

Conclusions:

The patient feels depressed, being conscious of his inner conflict towards objects from environment, he perceives as necessary and very appreciated $(\mathrm{d}+)$, but of which he cannot enjoy $(\mathrm{m} \pm)$.

\section{Psychodynamic Interpretations:}

The patient is regressed, blocked in a point situated most probably in the period of anal development, coprophilia and "fixation" for faecal matters representing a modality of control, the only power he has over his body. An animal instinct to revenge and territory marking can be 
identified, a pathology of containment. Given the incapacity of adults to offer him attachment, the person in question reaches to discharge his discontent in a physical manner.

The evolution of schizophrenia is an old one, in which we identify the symbolic significance of happiness theft when he lost his antivirus, namely protection.

His thinking is a paranoid one, with delusional persecution ideation, influence and insertion fo thoughts, occasionally associating suicidal preoccupations. Obsessive ruminations represent a seriousness prognostic. We identify hyperesthesia and a slowed time perception, a crucifixion beyond its passage (feeling of atemporality of the schizophrenic person). During acute moments of disorder, the patient's pathology runs in the sensorial-kinesic register, with slowness reaching up to the incapacity to perform movements, when there is the risk of cathatonisation.

We can notice Chaslin hypermnesia mentism, when the person in question cannot stop his representations, thoughts and memories that are coming in an embarrassing and parasite manner, subsequently being overlapped with Kandinsky Clerambault syndrome (pseudohallucinations, delusional relationship ideas, insertion of thoughts and xenopathic control). The adjacent anguish feeling determines the patient not to want any contact, at limit, nothing to enter, nothing to exit from his inner being.

We can identify the Ist rank symptoms of schizophrenia (according to Kurt Schneider), and in Gruhle's vision, we can speak of a paralysis of Ego, which represents an interruption in psychic life, determined by the cessation of consciousness flow, with the loss of feeling of his own activity and autonomy feeling, next to "thinking or acts that happen spontaneously, independently of his will and which sometimes can escape the conscious record". [16]

From the positive dimension of schizophrenia, we note external influence syndrome, the patient feeling prevented/influenced by his parents in all he does.

Complementarily, we can identify the transparency syndrome, in which the subject feels the occurrence in his consciousness, without his will, of some thoughts he perceives as alien from himself, imposed from exterior, by others.

\section{Conclusions and Recommendations}

\section{Differential OCD Diagnostic}

In DSM V, one renounces to criterion $\mathrm{B}$, which mentions that along OCD evolution, it is required that the individual permanently recognises the thoughts as being excessive or irrational, adopting the idea that the insight can oscillate. Therefore, when the individual is far from the anxious stimulus, he manages to be more critical.

Disorder criticism refers to the awareness of the negative consequences of the disorder, the individual being capable of insight on the negative impact the compulsions have on his own life and intimates. At the same time, the individual considers his preoccupations as being exaggerated and time-consuming. 
In case of intrusive thoughts, the individuals are scared that they had such ideas, there being a negative assessment related to his own person: "What kind of person am I if I had such thoughts?". In most cases, these ideas have aggressive connotations, blasphemies and perverse thoughts, which leads both to behavioural compulsions, and to mental compulsions.

These processes are energy-consuming, the person in question trying to calm down as regards the said thought or trying to understand if he really wants or not that thing, which leads to ruminations in the process of simulation in mind, to check if the said situation leads him or not to satisfaction. Being obsessive, only one simulation will not be sufficient for him, so that he will try many times, which will lead to the increase of intrusiveness in intensity and frequency, by adding details.

Compulsions are noticeable behaviours or mental acts to prevent or neutralize the threat, being different from those of control of drives that leads to pleasure.

In the case of impulsive obsessions, the patient resorts to particular acts, deprived of reasoning, inacceptable or ridiculous because the free manifestation of these drives would have negative consequences, by opposition, the individual charges emotionally, being awestruck and panic of not responding to impulsive tendency, of not committing the act under the form of a compulsion. [17] To defend against committing impulsive acts, the patient usually resorts to certain actions meant to free, to discharge the tension and to temporise the obsessive drive. [18]

By these rituals, the obsessive act is carried out in a form, being exercised against the will of the individual, dominating the conscience until they are completed, and if the patient tries to remove them, there appears a state of excruciating anxiety. [19] The rituals consisted of actions succeeding in a certain order, always on the background of a marking anxiety, which attenuates only if the patient fulfils that process of actions, and failure to fulfil these rituals creates him a state of anxiety that makes him incapable of fulfilling the action undertaken. [20]

Another characteristic of compulsions refer to their persistency and repetitiveness, often being ritualised - if the person in question makes a wrong step, the entire process is resumed from the beginning. The acts are reasoned and intentional, being different from automatic behaviours, mechanical, which are of neurological nature. [21]

In certain conditions, the individual can defer or can renounce to the ritual performance - for example, if the patient feels embarrassed to implement them in a certain context. In addition to compulsive acts, he also resorts to avoidances, distractions, insurance requests, suppression of thoughts.

The delusional idea is distinguished from the obsessive idea by the mode of occurrence in thinking. The delusional idea expresses clearly, there being the belief that cannot be influenced by external reality that leads to delusional behaviour, coming this from the inner side of the individual.

The obsessive idea besieges thinking, erupts and imposes from outside of consciousness, even if it is in disagreement with it. There is the capacity of recognition of its parasite character and a fight or an opposition is attempted or wanted. [22] 
Both types of ideas are accompanied by anxiety. In the present case, it is a challenge in itself to differentiate in the patient's speech his psychotic bizarre behaviour, occurred following delusional ideas and compulsions occurred following obsessive ideation.

In compulsion there is a tension state, when the fight is between impulsive tendencies, under the pressure of which the individual cedes and he relaxes committing the act, he relaxes feeling satisfaction. [23] In obsessionality, the force of repetition of the same need of satisfaction leads to a higher and higher tension, generated by the consequences that cold exist following the refusal of executing the compulsion. [24]

\section{References}

[1] Calvert, S.L., Strouse, G.A., Murray, K.J. (2006). Measuring Individual Differences in Empathy: Evidence for a Multidimensional Approach. Journal of Personality and Social Psychology, 44 (1).

[2] Swets M, D. J.-v. (2014). The obsessive-compulsive spectrum in schizophrenia, a meta-analysis and meta-regression exploring prevalence rates. Schizophr Res. Feb;152(2-3):458-68. doi: 10.1016/j.schres.2013.10.033. Epub 2013 Dec 19

[3] Kaplan, B., Sadock,V. (2001): Pocket Manual of Clinical Psychiatry. Third Edition. Bucharest: Medical Publishing House.

[4] Schirmbeck F, Z. M. (2013). Comorbid obsessive-compulsive symptoms in schizophrenia: contribution of pharmacological and genetic factors. Front Pharmacol. Aug 9; 4:99. doi: 10.3389/fphar.2013.00099. eCollection 2013

[5] Davison, G.C., Neale, J.M. (1998). Abnormal Psychology, Seventh Edition. New York, NY: John Wiley \& Sons, Inc.

[6] Calvert, S.L., Strouse, G.A., Murray, K.J. (2006). Empathy for adolescents' role model selection and learning of DVD content. Journal of Applied Developmental Psychology, 27.

[7] Seedat F, R. J. (2007). Prevalence and clinical characteristics of obsessive compulsive disorder and obsessive compulsive symptoms in Afrikaner schizophrenia and schizo-affective disorder patients. Afr J Psychiatry (Johannesbg). Nov;10(4):219-24.

[8] Frick, A., Gingnell, M., Marquand, A.F., Howner, K., Fischer, H., Kristiansson, M., Williams, S.C.R., Fredrikson, M., Furmark, T. (2013). Classifying social anxiety disorder using multivoxel pattern analyses of brain function and structure. Behavioral Brain Research, 259.

[9] TianHang Zhou, B. B. (2016). Schizo-Obsessive Disorder: the epidemiology, diagnosis and treatment of comorbid schizophrenia and OCD. Institute of Mental Health, Peaking University, Beijing, China.

[10] Tandon R, K. M. (2008). Epidemiology and etiology- Schizophrenia "just the facts" what we know in 2008. Schizophrenia Research 100 (2008) 4-19

[11] Ucok A, C. M. (2011). Obsessive compulsive disorder and symptoms may have different effects on schizophrenia. Prog Neuropsychopharmacol Biol Psychiatry. Mar 30;35(2):429-33. doi: 10.1016/j.pnpbp.2010.08.021. Epub 2010 Sep 8

[12] Sterk B, L. K. (2011). Obsessive-compulsive symptoms in first episode psychosis and in subjects at ultra-high risk for developing psychosis; onset and relationship to psychotic symptoms. Aust $\mathrm{N}$ Z J Psychiatry. May;45(5):400-6. doi: 10.3109/00048674.2010.533363. Epub 2010 Nov 18.

[13] Hodges, S.D., Myers, M., Michael W. (2007). Empathy. In R.F. Baumeister and K.D. Vohs (Eds.), Encyclopedia of social psychology. Thousand Oaks, CA: Sage.

[14] Trifu S, Brăileanu D., Carp E.G., Chirilescu A., Mihai I (2015) Psychodynamic Particularities in Expressing Systematized Delirium in Paranoid Schizophrenia. Procedia - Social and Behavioral Sciences, Volume 203, 412-418, doi: https://doi.org/10.1016/j.sbspro.2015.08.315. 
[15] Trifu S., Trifu, A.C. Trifu A.I. (2017) Nevroglya and superior cognitive functions. Antidepressants and neuroplasticity. Journal of the neurological sciences. Volume:381 Supplement: S. Pages: 837837. doi: https://doi.org/10.1016/j.jns.2017.08.2355

[16] Öhman, A. (2008). Fear and Anxiety: Overlaps and Dissociations. In Lewis, M. \& Haviland-Jones, J.M. \& Feldman Barrett, L. (Eds.) Handbook of Emotions, Third Edition. New York, NY: The Guilford Press.

[17] Hettema, J.M., Prescott, C.A., Myers, J M., Neale, M.C., Kendler, K.S. (2005). The structure of genetic and environmental risk factors for anxiety disorders in men and women. Archives of general psychiatry, 62(2).

[18] Balint, M., Ornstein, P.H., Balint, E. (1972). Focal Psychotherapy, an example of applied psychoanalysis. London: Tavistock.

[19] Banissy, M.J., Kanai, R., Walsh, V., Rees, G. (2012). Inter-individual differences in empathy are reflected in human brain structure. NeuroImage, 62.

[20] Dichter, E. (1972). Motivations and Human Behaviour. Paris: Punli-Union.

[21] Alkozei, A., Cooper, P.J., Creswell, C. (2014). Emotional reasoning and anxiety sensitivity: Associations with social anxiety disorder in childhood. J Affect Disord. Jan; 152-154: 219-228. doi: 10.1016/j.jad.2013.09.014

[22] Goldin, P.R., Gross, J.J. (2010). Effects of Mindfulness-Based Stress Reduction (MBSR) on Emotion Regulation in Social Anxiety Disorder. Emotion, 10(1).

[23] Samuels J, N. G. (2000). Personality disorders and normal personality dimension in obsessivecompulsive disorder. Br J Psychiatry. Nov;177:457-62. Br J Psychiatry. 2000 Nov; 177:457-62.

[24] Mar, R.A., Oatley, K., Hirsh, J., de la Paz, J., Peterson, J.B. (2006). Bookworms versus nerds: Exposure to fiction versus non-fiction, divergent associations with social ability, and the simulation of fictional worlds. Journal of Research in Personality, 40.

\footnotetext{
*Corresponding author.

E-mail address: dragoimiruna1@gmail.com
} 